\title{
GENDER GAP IN SUB-SAHARAN AFRICA, REMINISCENCE OF RURAL EXTENSION AND ADVISORY SERVICES: DELINEATION, CHALLENGES AND STRATEGIES
}

\author{
Agholor, A. I. ${ }^{1}$
}

Correspondence author: I. Agholor. Email: Isaac.agholor@ump.ac.za

\begin{abstract}
The paper examines the delineation and variation in the gender gap and agricultural development in sub-Saharan Africa, highlighting precise challenges in the provision of gendersensitive rural advisory services and offered strategies for gender mainstreaming for rural agricultural advisory services. Literature on the gender gap and advisory services were extensively reviewed. The result of the study revealed that improving gender equity through agricultural production may translate into a contribution towards poverty reduction and improving sub-Saharan African economies. In addition, proper designing of extension and rural advisory services programmes could be a promising strategy for terminating the existing gap between men and women in agriculture. The customary laws, socio-cultural and religious norms, and gender-blind policies that often inhibit women from enjoying their rights and access to and control of productive resources, economic opportunities and decision making must be repelled. The paper concludes that equitable organisational culture underpinned by organisational policies must be developed. An inclusive enabling atmosphere is also critical in the provision of gender-sensitive rural advisory services. It is recommended that the enactment of policies that will erase the gender gap in African agriculture could be beneficial, not only for women, but also for their families and communities in sub-Saharan Africa.
\end{abstract}

Keywords: Advisory services, Challenges, Gender gap, Rural extension, Strategies

\section{INTRODUCTION}

In Africa, about $90 \%$ of the population are involved in agriculture which accounts for almost one-third of the continents' Gross Domestic Product (GDP), and two-thirds of the population rely mainly on agriculture for income (World Bank, 2013). There is substantial empirical evidence suggesting that growth in Africa's agriculture is 2-4 times more result-oriented at directly alleviating poverty in contrast to other sectors (United Nations (UN), 2013). However, agriculture in sub-Saharan Africa has not lived up to its potential, instead it is wallowing in poor investment and inadequate recognition by policy makers (Carletto, Jolliffe \& Banerjee, 2013).

The persistent gender gap present in farming activities constitutes a major obstacle to agricultural growth and development in sub-Saharan Africa. Almost 43\% of the labour force in sub-Saharan Africa's agricultural sector are made up of women, but their activities in farming are reduced to unpaid family labour, and as a consequence, they are in many cases excluded from agricultural statistics (Food and Agriculture Organisation of the United Nations

\footnotetext{
${ }^{1}$ Senior Lecturer, Faculty of Agriculture and Natural Sciences, Department of Agricultural Extension and Rural Resource Management, University of Mpumalanga, Nelspruit, South Africa, Email: Isaac.agholor@ump.ac.za or Isaacagholor@gmail.com
} 
(FAO), 2011; International Fund for Agricultural Development (IFAD), 2011). Owing to structural barriers, women are noted as low producers as compared to their male counterparts (World Bank, 2012). There are distinct and critical areas where gender inequalities should be accentuated and heightened to ensure sustainability of livelihoods. Amongst numerous issues responsible for under performance of women in agricultural production, is their low access to productive resources exacerbated by discrimination emanating from customary laws and institutions in the areas of inheritance and property rights (Meinzen-Dick, Quisumbing \& Behrman, 2014). According to Ragasa (2014), despite concerted efforts to mainstream gender into agricultural extension services, women are still restricted from learning opportunities provided by rural advisory services (RAS). The FAO survey in 1989, which covers 97 countries, asserted that only $5 \%$ of available local extension resources were accessible and directly linked towards women. Sufficient evidence is available to showcase that closing this gender gap could release the locked productive potentials of women in agriculture. According to FAO (2011), if women had similar access to the means of production as their male counterparts, they could maximise yields on their farming business by $20-30 \%$ and subsequently multiply output by an average of $3 \%$.

The increases in women productive capacity is dependent on changes in gender relations and successful commitment of men who must see themselves as partnering beneficiaries and sharing of the means of production (Farnworth \& Colverson, 2015). Devoting attention to female farmers and introducing policies that will close the existing gender gap in African agriculture could produce substantial benefits for women and their families. Terminating the gender gap could help alleviate poverty and increase food security for Africa's growing population. According to the FAO (2011) report, the productive achievements of increases in agricultural production could relieve between 100 and 150 million people out of poverty and hunger.

Moreover, women's input to food security exceeds their agricultural production levels because of the supportive role offered at household level. Women invest more in the family as compared to their male counterparts (World Bank, 2012). Studies on gender reveals a progressive correlation between women's empowerment and feeding outcome, whereas negative correlations exist when women are disempowered (Van Den Bold, Quisumbing \& Gillespie, 2013). These results led to the acknowledgement of the necessity of empowering women, including through RAS (FAO, 2013). The determination to achieve women's empowerment in the perspective of agricultural production must take into cognisance the gender roles and intrahousehold differences since household decision making processes and workload differ (Bishop-Sambrook, 2014).

\subsection{Objectives of the study}

Improving gender equity in agricultural production may translate into poverty reduction and an increase in sustenance. The United Nation's Millennium Development Goals placed gender equality as a top priority for global agricultural development thus, emphasising the promotion and empowerment of women. In a similar vein, the World Development Report (WDR) concludes that gender impartiality is an essential development tool and remains a contributory factor to increased output as the evidence is clear that gender equality can enhance productivity and improve development outcome (World Bank, 2012). Against this backdrop, the current study succinctly delineates gender gaps which are reminiscent of RAS in sub-Saharan Africa. 
The objectives of the paper are as follows:

1. Examine the disparity in the gender gap and agricultural development in sub-Saharan Africa.

2. Highlight the challenges for mainstreaming gender into rural advisory services.

3. Determine strategies for gender mainstreaming in agricultural advisory services.

\section{METHODOLOGY}

The study reviewed relevant literature by concentrating on appropriate research results, journal articles, and FAO papers on gender gaps and RAS in sub-Saharan Africa. Secondary sources such as books on gender gaps and gender-sensitive RAS were also extensively reviewed.

\section{RESULTS AND DISCUSSION}

This paper delineates the gender gap and agricultural development in sub-Saharan Africa, highlighting precise challenges in the provision of gender-sensitive RAS and offers strategies for gender mainstreaming in agricultural advisory services. The results show that despite underrating women's productive role in agricultural production, providing support for women farmers and introducing policies that will close the existing gender gap in African agriculture could produce substantial benefits for communities in alleviating poverty and achieving food security. Findings from the study also provide direction on the factors that should be addressed in order to reduce the existing gender gap and thus increase opportunities for female farmers in sub-Saharan Africa.

\subsection{Delineation of the gender gap and agricultural development in Africa}

In most of sub-Saharan Africa, agriculture continues to be the main source of local economies and generation of income and food security. Amidst food security and agricultural production, most women in Africa continue to play a very important role. However, gender inequalities that manifest in the form of inadequate access and control of financial and agricultural resources largely inhibit agricultural intensification (UN Women, 2015).

UN Women (2015), on the cost implication of the gender gap in Malawi, Tanzania and Uganda, provided expository evidence and found that decreasing the gender gap contributes immensely to the amelioration of poverty. The study further quantified the cost in areas of loss in growth and estimated the societal economic gains if the gender gap in agriculture is effectively checked. However, there is also sufficient evidence to show that there is a link between closing the gender gap and economic empowerment of women vis-à-vis other developmental initiatives such as sustainable agriculture and increased economic performance (UN, 2015). In continuance of the findings, the closure of the gender gap in agriculture will push as many as 238 000, 80000 and 119000 small-scale farmers in Malawi, Tanzania and Uganda, respectively, out of poverty.

There are also striking avenues of opportunities for action with respect to climate vagaries and climate-smart agriculture and mitigation differentials, and if recognised will help close the gender gap and enhance women empowerment. The Sustainable Development Goals (SDGs) of the United Nations have offered an opportunity for allowing inclusive development approach which has also incorporated policy recommendations that gives impetus and support to the achievement of SDGs. Some of these goals include empowerment of women and girls as well as enhancing the objectives of the Comprehensive Africa Agricultural Development 
Programme (CAADP). The report of the SDGs further provides sufficient direction on the factors that should be addressed in order to ameliorate the existing gender gap and subsequently increase opportunities for female farmers in sub-Saharan Africa (UN, 2015).

In most countries, agricultural personnel, senior managers and policy creators are men, and the viewpoints and needs of rural women are not always considered (Beintema, 2014). In a recent study of 64 countries for 2003-2008, it was found that $23 \%$ of women were agricultural research personnel and 14\% were senior managers (Meinzen-Dick et al, 2011). The gender imbalance in management positions implies that resolutions about research agendas and other policies rest only on men, with minimal contribution from women. Resource allocation to men are not congruent with that of women, and as a result, the negotiating power within the household in terms of resource allocation can affect the general well-being of the family (Van Den Bold et al, 2013).

\subsection{Challenges in the provision of gender-sensitive rural advisory services}

Rural advisory services (RAS) is concerned with solidification of capacities, advancement of innovations, and empowering of rural communities. In the traditional setting, RAS provide information in areas of adoption of agricultural technology, knowledge and access to markets, farm inputs provision and financial services, and assisting farmers to improve their livelihoods (Modernising Extension and Advisory Services (MEAS), 2013). Through gender-sensitive RAS, women can acquire sophisticated agricultural techniques, and gain access to productive farm inputs and markets. However, there are numerous challenges which inhibit women's abilities to gain information, earn and have control over their income, purchase or access farm inputs, establish networks with other relevant agricultural service providers, and to participate in agricultural commodity groupings. These challenges are extensively discussed in this paper.

\subsubsection{Non-recognition of women as genuine rural advisory services clients}

General apathy exists on the part of RAS agents on whether female farmers should be provided with services or be considered as a legitimate audience in sub-Saharan Africa. Instances are evident where RAS agents engage with male farmers more regularly than their female counterparts because of the common misconception that women play a less important and obscured role in agriculture. It is also the assertion of RAS agents that male headed households should be prioritised in terms of extension service delivery with the intention that the advice and services given to men will filter down to the women in the long run (Gesellschaft für Internationale Zusammenarbeit (GIZ), 2012). The misunderstanding that women's role in agricultural production is equal or similar to household chores ignores considerable evidence of women's input to farming. In the traditional setting, most crops produced by women are either consumed within the household or sold locally at the farm gate, thereby overlooking the economic importance of their output.

In some communities, cultivated crops are classified as "women's crops" and "men's crops" which allows male farmers the impetus for the sale of the farm produce (Farnworth \& Colverson, 2015:21). In most sub-Saharan Africa, RAS providers engage women with only innovation and services related to home garden activities and backyard poultry, since they assume that women are basically suited for gardening activities. Owing to this approach, women's role in agriculture is underrated and they are not recognised as important clients for RAS. The enunciated selection criteria for receiving RAS makes it increasingly difficult for 
women to access advisory services. For example, in Kenya, a study found that RAS recipients were selected on the basis of landholding size, capacity to buy farm inputs, and literacy level (Manfre et al, 2013). In some cases, the selection may be done by community leaders who usually show preference for men due to the socio-cultural norms and values that recognises men as heads in the community. Therefore, women receive fewer services from RAS as compared to the men.

\subsubsection{Time burden and mobility limitation}

In many countries in sub-Saharan Africa, women take full participation in household chores comprising of cleaning, food preparation, childcare, and taking care of the sick and elderly in the household (Manfre, 2012). In addition, the collection of water and firewood, tending to pets, backyard gardens, and local level crop processing are left in the hands of women (ActionAid, 2013). These duties assigned to women consume a lot of their time and reduce their participation in RAS and agricultural activities. In a study by IFPRI on Uganda's National Agricultural Advisory Services (NAADS), it was reported that time burden was amongst the limiting factors hindering women's access to agricultural extension services (Meinzen-Dick et $a l, 2014)$. Comparatively, there is a disproportionate load of work undertaken by women as compared to the men in most households. In many instances, the time and effort put in by women in work related activities is higher than that of the men. For example, a study conducted in Cameroon found that women spent 12 hours on activities that fetch income and more than 50 hours on agricultural activities and household chores on a weekly basis. This is in comparison to men who spent 22 hours and 9 hours respectively (Arora \& Rada, 2013).

In addition, female farmers have restricted access to transportation coupled with the existing social and cultural barriers which makes it impossible for them to travel unaccompanied outside the community boundary (FAO, 2011). The study by FAO in Zambia found that women were unable to participate in agricultural extension training organised by the extension service department due to transport problems and difficulty in leaving the community (FAO, 1996). The time constraints experienced by women and mobility problems make it impossible for them to receive training and attend RAS programmes and this negatively impacts agricultural development.

\subsubsection{Inadequate level of literacy}

There has been steady growth and progress in the area of children education in sub-Saharan Africa, but adult female education is still problematic. According to World Bank statistics, women still have lower average literacy rates than men, despite the $89 \%$ increase over a 12 year period (World Bank, 2014). This lower rate is attributable to structural imbalances, communal image, and expectations. Thus, women in developing countries have less access to formal education as compared to their male counterparts. Literacy is directly linked to agricultural intensification as educated farmers tend to adopt innovation and accept participation in agricultural programmes that involves the application and use of documented materials (Hassan, Tanvir \& Naeem, 2014). Intertwined with literacy is the language barriers which also debar women from accessing and profiting from RAS. For example, in most countries in sub-Saharan Africa, RAS adopt the national language as a means of instruction and delivery of services. In some instances, the language may not be understood by everyone and translation of training materials into local dialects may not be possible. Some communities have rooted cultural preferences about a particular language adopted for training, as was the 
case with Iraq, where the Kurdish participants in extension training were reluctant to adhere to training instructions in Arabic (Abi-Ghanem et al, 2013). Therefore, it is pertinent to allow for good interpretation, translation and understanding of languages used in the delivery of instructions as this will affect women's aptitude for accepting new ideas and information.

\subsubsection{Representation, voice and advancement of women's interest}

Membership-based institutions such as the producer organisations, farmers' unions, and cooperatives are tailored towards representing the interest of members. Participation in these organisations is important for female farmers to receive information, integrate, and engage in collective action and decision making, build networks and social capital, and reaching out to the Department of Agriculture and policy makers. However, available evidence justifies the under-representation of women in these rural organisations and therefore, women are side-lined from the services offered by RAS agents (Kaaria \& Osorio, 2014). In a study conducted by the World Bank/IFPRI, it was found that $24 \%$ of men and $4 \%$ of women in Ethiopia and Ghana are members of farmer cooperatives, while in Ethiopia, it was further stated that men are five times more inclined to hold leadership positions within farmers' groupings or associations (World Bank, 2010). FAO (2014) also reported that socio-cultural customs and societal values regarding gender discrimination accounted for diminishing women participation in producer organisations in sub-Saharan Africa. Most households are headed by males and the producer organisations' rules of entry or admission may only allow one person per household as a member. In selecting who represents the household, the male is given preference as household head, because customs of the community prohibit females from taking headship where men are available. This phenomenon reduces the chances of women participation in farmers' cooperatives and producer organisations.

The importance of cooperatives and producer organisations cannot be overemphasised as it has the inherent potential for women empowerment in the areas of representation and invigorating the voices of women. However, owing to discrimination and gender preferences, this is not achieved. Therefore, women generally resort to finding and belonging to other organisations such as church groups, women associations, and community-based organisations (CBOs) that may not have relevance to their needs in terms of information and empowerment. Women in most rural communities are saddled with multiple barriers to participation in decision-making occurring at different levels of the society. The hurdles are reminiscent of the cultural norms and belief, age, ethnicity and sexual orientation. The impact of women is negatively perceived by most communities and their contribution in decision making is often fraught with uncertainty, coupled with their minimal numerical strength during community meetings. The intricacies of women's and men's social roles and differentiation needs to be recognised and the systematic obstacles that isolate women in decision making should be addressed.

\subsubsection{Disparity in human resources and staffing}

In Africa, there is diversity of culture which translates to access in participation in rural community projects and development. In some African cultures, it is insupportable for male RAS advisors to converse with women in the local villages, while in other cultures, women are more at ease discussing and building rapport with females. In some African societies, it is also forbidden for women to move out of their nuclear family to meet with men (Carter \& Weigel, 2011). The inadequate female RAS advisors disallows women from benefitting or receiving vital information. The affirmation here is that women feel more comfortable to discuss and 
express their views on subjects moderated by women advisors. However, there are very few female agricultural advisors available. As noted by FAO (2011), only 15\% of RAS advisors in Africa are female. It bears noting that this phenomenon where women prefer female advisors varies by region, cultural milieu and location (Meinzen-Dick et al, 2011). The concept of gender equality embodies equal access to existing resources and opportunities by men, women, boys and girls, but prejudiced customary and statutory laws, socio-cultural and religious tenets, and gender-blind regulations inhibit women from accessing and relishing their rights. These occurrences result in the disparity between women and men in terms of access to productive resources, economic opportunities, participation in community development, and decision making.

\subsubsection{Gender-blind technology}

The gender-neutral technologies are prone to affecting power relations, subsequently initiating reduction of access by women. A study found that gender-blind technical modernisations are inclined to assist more men as compared to their female counterpart in Africa (Quisumbing \& Pandolfelli, 2009). In Turkey, the participation of women in agriculture decreased substantially due to the socio-cultural values and modern technologies which were not designed for use by women (Ozcatalbas \& Akcaoz, 2010). In addition, the innovation systems referred to as "stabling" techniques, which includes intensive animal health care programmes involving food supplements for animals to increase milk production in Senegal, was rejected by women because it demands extra labour (Peterman, Behrman \& Quisumbing, 2010). In general, women will value technical innovations only if these innovations will increase productivity, without extra labour and minimal time commitment.

\subsubsection{Culture within an organisation}

Government, Non-Governmental Organisations (NGOs), private sectors, and farmers' groups in Africa are saddled with the responsibility of providing RAS. These RAS providers have an inherent organisational culture which governs them and is expressed via a set of value systems, beliefs, practices and ideologies. Undoubtedly, the culture of an organisation influences its workers' views of gender roles in their work environment. In addition, gender-blind organisations deliver gender-biased RAS. There are judgement biases about RAS records and statements which mostly assumed that farmers are men. In line with this assumption, most extension concepts are planned as cascading into a biased decision-making which favours men (Global Forum for Rural Advisory Services (GFRAS), 2014). A study by Buchy and Basaznew (2015), found that the inadequate clear procedures to address gender equality in Southern Ethiopia resulted in poor extension service delivery to female farmers in the region. In most cases, women are constrained to work in government agencies which are dominated by males. This set up leads to unequalled participation of women in decision making processes. In Pakistan, for example, a study conducted by FAO (2011) found that female extension agents were not promoted during their 17 years of service and were not given the opportunity to develop their knowledge and skills (Consultative Group for International Agricultural Research (CGIAR), 2012). These factors rigorously limit women's capabilities to partake in decision making processes. Cohen and Lemma (2011), in their study on the impacts of decentralisation of RAS, also found that organisational cultures about gender varied greatly between four study districts in Ethiopia, culminating into different levels of effectiveness. 
In sum, gender equity, which refers to impartiality and fairness in the sharing of benefits, including agricultural extension and advisory services and duties between women and men, faces serious challenges in organisational culture. However, the informal aspect which also includes biased norms and values that allow prohibitive practices amongst females are the most difficult to tackle (Rao, 2012).

\subsection{Strategies for gender mainstreaming and agricultural advisory services}

\subsubsection{Perception of female farmers}

Farmers are often perceived by RAS agents as the head of farming households, the owner of the land that is farmed, or the individual who is entitled to the revenue earned from the sale of produce. A study showed that these biased delineations poses challenges to the delivery of RAS to women for several reasons: "women might be landless, and they may provide their agricultural labour to the plots cultivated by male members of the household, or they may be excluded from access to and decisions over household income derived from the sale of the farm products" (Manfre, 2012:25). The narrow definition and use of the term 'farmers', may exclude women from accessing RAS because women are not considered as 'real' farmers. In addition, the selection criteria for beneficiaries of RAS often pose as hindrances to women participation in RAS. For these obvious reasons, erroneously pointing at 'farmers' in a gender-blind approach can lead to women's imbalanced and unfair access to RAS. This exclusion calls for revising how RAS agents classify or define farmers to accommodate female farmers. It is also imperative that RAS agents recognise that female farmers are a heterogeneous group, demanding and requiring a variety of strategies to address their distinct needs.

\subsubsection{Responding to women's time burden and mobility limitation}

In some rural parts of Ethiopia, men assume a great deal of control over women's mobility, making it difficult for women to attend RAS training due to mobility limitation, heavy household workloads, and cultural issues (Woldu, Tadesse \& Waller, 2013). Therefore, men were encouraged to bring their wives to the training sessions organised by the EMPOWER programme in Ethiopia and this was able to escalate women's access to innovations (Gallina, 2010). Furthermore, it is better to deliver training directly to women at their homestead or close to their plots of land used for cultivation (Carter \& Weigel, 2011).

\subsubsection{Addressing the inadequate level of literacy amongst women}

Adult literacy classes should be planned to improve literacy rates amongst women. The planning should take into cognisance the homogeneity of lessons and appropriate methods of delivery to ensure continuity. However, the success of these initiatives requires collaboration with NGOs such as the Digital Greens and Access Agriculture which are known for the support and production of farm videos to assist local farmers (Harvin, 2013). These online demonstrations, where good farming practices are shown, assist in communicating information, which provides access to knowledge amongst less educated local women. The distinctiveness of these online teaching videos is that the messages delivered from the videos are specific to the farmers' needs and circumstances. Furthermore, with the help of a facilitator, farmers can select and adopt innovations after watching the videos, as training materials assembled in pictures, plays and stories are much easier to understand (Carter \& Weigel, 2011). Messages delivered by RAS agents in the simplest possible form with local content have 
proven to be very effective. In Kenya, for example, women with lower literacy levels performed better than men in soil replacement skills because of the pattern of delivery adopted in overcoming their inadequacies (Quisumbing \& Pandolfelli, 2009).

\subsubsection{Strategies for representation, voice and advancement of women's interest}

The adoption of participatory approaches becomes paramount to allow for women's voices to be heard and incorporated in programme planning and decision making processes. The sharing and decentralisation of power in communities must adopt a gender sensitive approach to allow for social cohesion and empowerment. In sum, an innovative political will aimed at allowing local access to decision making processes and promotion of women involvement should be created to promote strong participation and prosperous communities. The concepts of gender equality must reflect balanced participation, and decision making that reflects the needs and concerns of men and women at equal ratios, for the well-being of the entire community.

The opportunity for women to form single-sex groups should be encouraged. The formation of these groups will afford women ample opportunity to voice their feelings in circumstances where the presence of men may be intimidating (Manfre et al, 2013). The formation of singlesex groups will also assist women to build self-confidence and self-esteem. In addition, good processes that encourage women's involvement in leadership of most farmers' organisations remains a laudable strategy (Herbel et al, 2012; MEAS, 2015). Such processes may involve allowing quotas for women, or demanding membership participation with spouses. Moreover, RAS agents could also ask men to bring their wives with for meetings, and be prepared to spend a larger portion of time with women, and also requesting the assistance of village chiefs to identify women in need of advisory services (Spring, 1986).

\subsubsection{Curbing the disparity in human resources and staffing}

In eliminating the disparity in staffing, adequate capacity development by making scholarships accessible for women in agriculture should be encouraged. Allowing a sizable increase in the number of female RAS agents and managers could bridge the gap in the ratio of male to female RAS agents. Government, organisations or institutions must be encouraged to set up quotas for employment of female staff in agriculture and related fields. The engagement of female extension advisors can also assist in overcoming biases about women's inactiveness, relative to men (Carter \& Weigel, 2011). Mentorship and career development programmes and facilitation of different workshops for women will go a long way in supporting and enhancing women's confidence, and this will also assist in growing the number of female RAS advisors. The existing career development programmes such as the African Women in Agricultural Research for Development (AWARD), the African Women Leaders in Agriculture and Environment (AWLAE), and the Uganda affiliate-Association of Uganda Professional Women in Agriculture and Environment (AUPWAE) should be strengthened to support and increase the number of female RAS advisors. Similar and additional career development programmes for women should be established.

\subsubsection{Addressing gender-blind technology}

The crafting of appropriate technology that is affordable, acceptable and user friendly for females and males are crucial and need to be taken into consideration. According to Quisumbing and Pandolfelli (2009), working out a reasonable baseline investigation at the 
household and community levels should be done before presenting and building a new technology for adoption as this will assist in assessing the gender impact. Gender awareness should be promoted at the research domain where the initiation and development of technologies are considered and nurtured. Farm implements that take cognisance of women's height, weight and ease of operation must be designed in such a way that it should lessen drudgery and time appropriated for farm operations such as seed-bed preparation, harvesting, fertilizer application, and weeding (FAO, 2001).

\subsubsection{Supporting a gender-sensitive culture within an organisation}

The organisational culture is diverse and encompasses norms, principles and cyphers of behaviour within an organisation that support gender equality. This cascades into how organisations display respect for diversity in the workplace, administration style, the presence of a documented equal opportunity policy, flexibility in work engagements, general leave policy, advancement of teamwork for both men and women as equal associates, and reassurance of gender-sensitive conduct. The implementation of the existing policy on organisational culture determines if RAS programmes will be gender-sensitive. In many cases, the absence of definite measures to address gender equality within an organisation accounts for the inadequate attempts to reach out to rural female farmers in Africa. The awareness, rationale and commitment to gender-sensitive organisational culture should be explicit to all employees. There should be alignment of institutional policy and implementation with organisational culture to be able to deliver a RAS gender sensitive programme (Buchy \& Basaznew, 2005; Mogues et al, 2009). It has also been suggested that participatory gender audits are pertinent for stimulating organisational awareness at personal and organisational levels on how to efficiently mainstream gender (International Labour Organisation (ILO), 2012). The proposed gender audit will assist in the identification of areas where gaps and challenges exist and offer plausible solutions. For example, the National Agriculture and Livestock Extension Programme (NALEP) of Kenya has developed a guide for mainstreaming gender in their agricultural sector (NALEP, 2010).

\section{CONCLUSION}

The paper succinctly delineated the gender gap, challenges, and highlighted strategies for mainstreaming gender into rural advisory services (RAS). The progression of agricultural extension and RAS to respond to the needs, aspirations and priorities of male and female farmers has been on discourse for decades. Previous studies have showcased the significant role of women in agricultural production. Women's productive role and time devoted to agriculture has been accentuated and acknowledged as equal to those of men in alleviating poverty and achieving food security. Enhancing gender equity through agricultural production may translate into contributing towards poverty reduction and improving sub-Saharan Africa's economies. It is also important to mention that by recognising these opportunities, most countries in sub-Saharan Africa have focused their attention towards addressing the gender gap in agriculture. However, despite their support and focus, efforts have not yielded the desired result.

This paper concludes that the limited voice and representation of women can be addressed by including women as legitimate RAS clients while organisations need to recognise them as service users in their own right. Furthermore, the selective criteria that excludes women from accessing RAS must be expunged. Social networks could also be developed as a useful tool for 
enhancing women's voice and in delivering of RAS. To increase the number of women RAS agents, the government and organisation should offer scholarships to encourage young females to study agricultural extension and rural resource management. Quotas could also be applied in the recruitment of women into agricultural fields and career enhancement initiatives that incorporate mentorship and training, and seminars can be of good support to women. RAS staff should be mindful of the relative impact of gender roles on their work and therefore gender mainstreaming should be critical in the provision of RAS.

Furthermore, the consciousness and recognition of the constraints faced by women are also very important. Strategies that will redress obvious disparity between men and women in the quest for productive resources, knowledge, technology, and economic opportunities must be recognised to allow for food security enhancement and poverty alleviation. In addition, proper designing of extension and RAS programmes could be a promising strategy for terminating the existing gap between men and women in agriculture. The customary laws, socio-cultural and religious norms, and gender-blind policies that often inhibit women from enjoying their rights and access to and control of productive resources, economic opportunities, and decision making must be examined and reviewed. Moreover, the UN Millennium Development Goals placed gender equality as a top priority for global development, emphasising promotion, women empowerment, and gender equality. In a similar vein, the World Development Report (WDR) concludes that "gender equality is a core development objective in its own right and remains a smart economy as the evidence is clear that gender equality can enhance productivity, improve development outcomes for the next generations, and make institutions more representative" (World Bank, 2012:5). Finally, equitable organisational culture underpinned by organisational policies should be developed.

\section{RECOMMENDATIONS}

The enactment of policies that will erase the gender gap in sub-Saharan African agriculture is recommended as this could be beneficial, not only for women, but also for their families and communities. An inclusive enabling atmosphere is also critical in the provision of gendersensitive RAS. In addition, it will enhance food security amongst households. Lastly, the sharing and decentralisation of power in communities should adopt gender sensitive approaches to allow for social cohesion and empowerment. However, numerous empirical studies and recent scholarly discoveries present similar, if not the same, challenges for the provision of gender-sensitive RAS. This raises concerns about how effectively the suggestions and recommendations provided in the last decade have been accentuated and applied.

\section{REFERENCES}

ABI-GHANEM, R., HALL, J., CARPENTER-BOGGS, L., KOENIG, R.T., ULLMAN, J.L. \& MURPHY, K.M., 2013. Access to agricultural inputs, technology and information, communicating with farmers, and the role of women in agriculture: Perceptions of Iraqi. JIAEE., 20(1):1-13.

ACTIONAID, 2013. Making care visible: Women's unpaid care work in Nepal, Nigeria, Uganda and Kenya. Available from: www.actionaid.org/publications/making-carevisible 
ARORA, D. \& RADA, C., 2013. Gender differences in time and resource allocation in rural households in Ethiopia. Paper presented to The Association for the Study of Generosity in Economics. Philadelphia, United States of America.

BEINTEMA, N., 2014. Enhancing female participation in agricultural research and development: Rationale and evidence. In Gender in agriculture: Closing the knowledge gap (pp.393-409). Rome: Food and Agriculture Organization.

BISHOP-SAMBROOK, C., 2014. Why we need to look inside the family, in the international year of family farming. Available from: http://ifad-un.blogspot.it/2014/01/why-we-needto-look-inside-family-in.html

BUCHY, M. \& BASAZNEW, F., 2005. Gender-blind organizations deliver gender-biased services: The case of Awasa Bureau of Agriculture in Southern Ethiopia. Gen. Technol. Dev., 9(2):235-256.

CARLETTO, C., JOLlifFE, D. \& BANERJEE, R., 2013. The emperor has no data! Agricultural statistics in sub-Saharan Africa. Available from: http://mortenjerven.com/wp-content/uploads/2013/04/Panel-3-Carletto.pdf

CARTER, J. \& WEIGEL, N., 2011. Targeting women in Rural Advisory Services (RAS). Available from: www.shareweb.Ch/site/Agriculture/Food

COHEN, M.J. \& LEMMA, M., 2011. Agricultural extension services and gender equality: An institutional analysis of four districts in Ethiopia. IFPRI Discussion Paper No. 1094. Washington, D.C., United States of America.

CONSULTATIVE GROUP FOR INTERNATIONAL AGRICULTURAL RESEARCH (CGIAR), 2012. Building coalitions, creating change: An agenda for gender transformative research in development workshop report. Available from: http://pubs.iclarm.net/resource_centre/WF_3447.pdf

FARNWORTH, C.R. \& COLVERSON, K.E., 2015. Building a gender-transformative extension and advisory facilitation system in sub-Saharan Africa. Agri-Gender, 1(1):2039.

FOOD AND AGRICULTURE ORGANIZATION OF THE UNITED NATIONS (FAO), 1996. Improving extension work with rural women. Available from: www.fao.org/docrep/x0249e/x0249e00.htm\#TopOfPage

FOOD AND AGRICULTURE ORGANIZATION OF THE UNITED NATIONS (FAO), 2001. From farmer to planner and back: Harvesting best practices. Available from: www.fao.org/docrep/005/y0354e/y0354e00.htm\#TopOfPage

FOOD AND AGRICULTURE ORGANIZATION OF THE UNITED NATIONS (FAO), 2011. The state of food and agriculture 2010/2011. Available from: http://www.fao.org/docrep/013/i2050e/i2050e00.htm

FOOD AND AGRICULTURE ORGANIZATION OF THE UNITED NATIONS (FAO), 2013. Coping with the food and agriculture challenge: Smallholders' agenda. Available from: www.fao.org/fileadmin/templates/nr/sustainable-pathways/dco/coping

FOOD AND AGRICULTURE ORGANIZATION OF THE UNITED NATIONS (FAO), 2014. Family farmers: Feeding the world, caring for the earth. Available from: www.fao.org/docrep/019/mj760e/mj760e.pdf 
GALLINA, A., 2010. Gender-aware approaches in agricultural programmes: International literature review. Available from: www.sida.se/contentassets/5ecd73c4347846b890569e920b c24e1a/20103-genderAware-approaches-in160agricultural-programmes-8211-international-literaturereview_2924.pdf

GESELLSCHAFT FÜR INTERNATIONALE ZUSAMMERNARBEIT (GIZ), 2012. Gender and agricultural extension. Available from: https://www.giz.de/ fachexpertise/downloads/giz2012-en-gender-and-agricultural-extension.pdf

GLOBAL FORUM FOR RURAL ADVISORY SERVICES (GFRAS), 2014. Gender equality in rural advisory services. Available from: www.gfras.org/fr/component/phocadownload/category/17-gender.html

HARVIN, K., 2013. Lessons learned from locally produced videos - The approach of digital green in India. MEAS Case Study No. 7. Illinois, United States of America.

HASSAN, M.Z.Y., TANVIR, A. \& NAEEM, M.R., 2014. Obstacles to gender mainstreaming in agricultural extension in the Punjab, Pakistan. Int. J. Agric. Ext., 2(2):96-99.

HERBEL, D., CROWLEY, E., OURABAH, H. \& LEE, M., 2012. Good practices in building innovative rural institutions to increase food security. Rome: Food and Agriculture Organization.

INTERNATIONAL FUND FOR AGRICULTURAL DEVELOPMENT (IFAD), 2011. Rural poverty report 2011. Available from: www.ifad.org/rpr2011/report/e/ rpr2011.pdf

INTERNATIONAL LABOUR ORGANIZATION (ILO), 2012. A manual for gender audit facilitators: The ILO participatory gender audit methodology. Geneva: International Labour Organization.

KAARIA, S. \& OSORIO, M., 2014. Women's participation in rural organizations: Why is it important for improving livelihoods and sustainable management of natural resources? Nature \& Faune, 29(1):12-16.

MANFRE, C., 2012. ICT in agriculture sourcebook. Washington, D.C: World Bank.

MANFRE, C., RUBIN, D., ALLEN, A., SUMMERFIELD, G., COLVERSON, K. \& AKEREDOLU, M., 2013. Reducing the gender gap in agricultural extension and advisory services: How to find the best fit for men and women farmers. MEAS Discussion Paper No. 2. Illinois, United States of America.

MEINZEN-DICK, R., QUISUMBING, A.R. \& BEHRMAN, J.A., 2014. A system that delivers: Integrating gender into agricultural research, development, and extension. In Gender in agriculture: Closing the knowledge gap (pp.373-391). Rome: Food and Agriculture Organization.

MEINZEN-DICK, R., QUISUMBING, A., BERHMAN, J., BIERMAYR-JENZANO, P., WILDE, V., NOORDELOOS, M. \& BEINTEMA, N., 2011. Engendering agricultural research, development, and extension. Washington, D.C: International Food Policy Research Institute.

MODERNIZING EXTENSION AND ADVISORY SERVICES (MEAS), 2013. Extension and advisory service delivery for women's groups in Jordan: Assessing competencies and building social capital. Available from: https://sites.google.com/a/measextension.org/safety_2013_07_31/meas-offers/pilot-projects/gender-research-jordan 
MODERNIZING EXTENSION AND ADVISORY SERVICES (MEAS), 2015. Working with women's groups in Jordan - building networks and social capital. Available from: https://meas.illinois.edu/wp-content/uploads/2017/02/MEAS-PA-Report-Workingwith-Womens-Groups-in-Jordan-Building-networks-social-capital-March-2015.pdf

MOGUES, T., COHEN, M.J., BIRNER, R., LEMMA, M., RANDRIAMAMONJY, J., TADESSE, F. \& PAULOS, Z., 2009. Agricultural extension in Ethiopia through a gender and governance lens. IFPRI Discussion Paper No. ESSP2 007. Washington, D.C., United States of America.

THE NATIONAL AGRICULTURE AND LIVESTOCK EXTENSION PROGRAMME (NALEP), 2010. A guide for mainstreaming gender in the agricultural sector. Available from: $\quad$ www.nafis.go.ke/wp-content/uploads/2011/12/nalep-gender-mainstreamingguide.pdf

OZCATALBAS, O. \& AKCAOZ, H., 2010. Rural women and agricultural extension in Turkey. J. Food Agric. Environ., 8(1):261-267.

PETERMAN, A., BEHRMAN, J. \& QUISUMBING, A.R., 2010. A review of empirical evidence on gender differences in non-land agricultural inputs, technology, and services in developing countries. IFPRI Discussion Paper 975. Washington, D.C., United States of America.

QUISUMBING, A.R. \& PANDOLFELLI, L., 2009. Promising approaches to address the needs of poor female farmers: Resources, constraints, and interventions. World Dev., 38(4):581-592.

RAO, A., 2012. Sustaining women's agricultural livelihoods: Why can't global institutions get it right? In Women reclaiming sustainable livelihoods: Spaces gained, spaces lost. London: Palgrave.

RAGASA, C., 2014. Improving gender responsiveness of agricultural extension. In Gender in agriculture: Closing the knowledge gap (pp.411-430). Rome: Food and Agriculture Organization.

SPRING, A., 1986. Reaching female farmers through male extension workers in Malawi. Rome: Food and Agriculture Organization.

UN Women, 2015. Progress of the world's women 2015-2016. Available from: http://progress.unwomen.org/en/2015/

UNITED NATIONS (UN), 2013. World population prospects: The 2012 revision. Available from: https://population.un.org/wpp/

UNITED NATIONS (UN), 2015. The millennium development goals report 2015. Available from:

http://www.un.org/millenniumgoals/2015_MDG_Report/pdf/backgrounders/MDG\%20 2015\%20PR\%20Bg\%20SSA.pdf

VAN DEN BOLD, M., QUISUMBING, A.R. \& GILLESPIE, S., 2013. Women's empowerment and nutrition: IFPR Discussion Paper No. 1294. Washington, D.C., United States of America.

WOLDU, T., TADESSE, F. \& WALLER, M., 2013. Women's participation in agricultural cooperatives in Ethiopia. IFPRI Discussion Paper No. ESSP2 57. Addis Ababa, Ethiopia. 
S. Afr. J. Agric. Ext.

Vol. 47 No. 3, 2019: 46 - 60

http://dx.doi.org/10.17159/2413-3221/2019/v47n3a514
Agholor

(License: CC BY 4.0)

WORLD BANK, 2010. Gender and governance in rural services. Available from: http://doi.org/10.1596/978-0-8213-7658-4

WORLD BANK, 2012. World development report 2012: Gender equality and development. Available from: https://openknowledge.worldbank.org/handle/10986/4391

WORLD BANK, 2013. The World Bank and agriculture in Africa. Available from: http://webworldbank.org.wbsite/external/countries.africaext/0,contentmdk:21935

WORLD BANK, 2014. World development indicators: Education completion and outcomes. Available from: http://wdi.worldbank.org/table/2 
